\title{
Leis científicas são também leis da natureza?
}

\author{
RENATO CESAR CANI *
}

\footnotetext{
* Mestrando em Filosofia na UFPR

Bolsista (CAPES) renatocani@gmail.com
}

RESUMO Neste artigo, discuto duas versões de Realismo Nomológico (RN): o necessitarismo categorialista de Armstrong e o essencialismo disposicional de Bird e Ellis. De modo geral, o RN defende que as regularidades observadas pelas ciências (as leis científicas) são explicadas pela existência de fatos sobre o mundo que as fundamentam (as leis da natureza). Em primeiro lugar, argumentarei que a identificação das leis a relações de necessitação entre universais (Armstrong) implica sérias dificuldades, sendo a pior delas o quidditismo. Em segundo, tentarei demostrar como a tese segundo a qual as leis sobrevêm das essências disposicionais dos objetos (Bird e Ellis) fundamenta de modo mais satisfatório o caráter metafisicamente necessário das leis.

PALAVRas-chave Leis da Natureza, Realismo Nomológico, Essencialismo Disposicional.

ABSTRACT In this paper, I discuss two versions of Nomological Realism (NR): Armstrong's categoricalist necessitarianism and Bird's and Ellis' dispositional essentialism. Basically, NR holds that the uniformities observed by science (the scientific laws) are explained by the existence of facts about the world which ground them (the laws of nature). Firstly, I will argue that the identification of laws with necessitation relations among universals (Armstrong) entails serious difficulties, the worst of which being quidditism. Secondly, I will try to demonstrate how the account according to which laws supervene on dispositional essences of objects (Bird and Ellis) grounds the metaphysically necessary character of laws in a more satisfactory manner.

KEYWORDS Laws of Nature, Nomological Realism, Dispositional Essentialism. 


\begin{abstract}
Não há, entre as ideias que ocorrem na metafísica, outras mais incertas e obscuras que as de poder, força, energia ou conexão necessária, das quais nos é forçoso tratar a cada instante em todas as nossas investigações.

David Hume, Investigações sobre o Entendimento Humano, Seção VII, §3.
\end{abstract}

\title{
INTRODUÇÃO
}

Penso que grande parte das pessoas que se dedicam à filosofia concorda com o fato de que há regularidades na natureza. Enunciados como “A água ferve a $100^{\circ} \mathrm{C}$ ” ou “Os metais são bons condutores de eletricidade” expressam uniformidades que ocorrem com certa estabilidade e generalidade. Imagino, ainda, que haveria consenso sobre a afirmação de que esse tipo de regularidade fundamenta muitas das descrições e previsões científicas acerca dos acontecimentos do mundo. Assim, as leis científicas são compreendidas como enunciados gerais que expressam as regularidades relevantes ao domínio científico específico a que se referem.

Durante grande parte do século XX, o debate filosófico acerca do estatuto das leis científicas esteve ligado aos aspectos semânticos e lógicos desses enunciados gerais, bem como ao seu papel nas explicações científicas. Um dos problemas tratados nessa discussão é o da busca pela definição de critérios lógicos que permitiriam distinguir generalizações nomológicas (verdadeiras em virtude de uma lei) de generalizações acidentais (acidentalmente verdadeiras). Dito de outro modo, trata-se do problema de distinguir enunciados como “Todos os metais dilatam quando aquecidos" daqueles do tipo “Todas as pessoas nesta sala têm menos de 90 anos de idade”. De fato, Hempel e outros autores buscaram justificar essa distinção em termos sintáticos e/ou semânticos.

Mais recentemente, alguns filósofos passaram a abordar as questões relativas às leis do ponto de vista propriamente metafísico: se os enunciados que descrevem regularidades (isto é, as leis científicas) são verdadeiros, em virtude de que eles o são? Em outros termos, quais são os truthmakers dos enunciados nomológicos? De acordo com o Realismo Nomológico (RN), as leis da natureza são definidas como o fundamento metafísico das regularidades. Essa perspectiva é descrita como uma forma de realis- 
mo precisamente porque admite como real algo além das regularidades observáveis. Assim, se o enunciado segundo o qual "Todos os metais dilatam quando aquecidos" (ou outra generalização similar) for verdadeiro, o que o torna verdadeiro é um fato real acerca do mundo, isto é, uma lei da natureza. Em última análise, se o RN estiver correto, as leis da natureza são os truthmakers das leis científicas.

No entanto, o que são leis da natureza? Nesta comunicação, pretendo abordar duas perspectivas realistas que definem as leis de modo distinto. Segundo o necessitarismo categorialista, leis são relações de necessitação entre universais categóricos. Assim, dados os universais F e G (e.g. "ser um metal” e "ser dilatável mediante o aquecimento"), a lei que os conecta é o universal de segunda-ordem $N(F, G)$. Tal concepção foi defendida de modo independente por Dretske (1977), Tooley (1977) e Armstrong (1983). Por essa razão, tem sido denominada concepção DTA. Por outro lado, o essencialismo disposicional (ED) afirma que as leis da natureza são fundadas nas essências disposicionais dos objetos. Uma disposição é definida como a potência de manifestar determinada propriedade nas circunstâncias apropriadas. Ela é essencial ao objeto que a possui, uma vez que define uma condição necessária para que esse objeto seja classificado como membro de determinado tipo. Nesse sentido, a lei da dilatação dos metais, caso verdadeira, estaria fundada numa disposição essencial dos metais. A perspectiva essencialista das leis tem sido defendida por autores como Ellis (2002), Bird (2007) e Ghins (2013).

Ambas as perspectivas realistas contrastam com a visão que se costuma denominar regularismo. Nessa visão, as regularidades observadas não precisam de fundamentação ulterior, isto é, não há nada no mundo além das regularidades. Logo, o regularismo pode ser considerado uma variação de Antirrealismo Nomológico (AN). Com efeito, essa posição tem clara inspiração humeana, à medida que se vale dos argumentos céticos de Hume contra a ideia de que há conexões necessárias na natureza. Tal tese metafísica é denominada sobreveniência humeana, como define o regularista David Lewis: “Trata-se da doutrina segundo a qual tudo o que há no mundo é um vasto mosaico de questões de fato particulares, apenas um acontecimento seguido de outro." (LEWIS, 1986, p. ix). Para o regularista, portanto, tudo o que há são regularidades, não há leis da natureza para fundamentá-las. 


\section{LEIS FUNDADAS NOS UNIVERSAIS: A CONCEPÇÃO NECESSITARISTA}

A concepção necessitarista das leis se contrapõe ao regularismo à medida que fundamenta as uniformidades em relações entre universais. Com efeito, Dretske (1977) argumenta contra a definição regularista das leis como verdades universais dotadas de certa função sistemática no contexto científico. Para o autor, embora a visão regularista seja econômica do ponto de vista metafísico, por outro, não é capaz de caracterizar o poder explicativo das leis nem de explicar a verdade dos contrafatuais. Isso ocorre, na visão de Dretske, devido ao fato de a atribuição do estatuto de lei a algum enunciado não depende de condicionantes epistêmicos: “O uso de uma sentença como expressão de uma lei depende de considerações epistemológicas, mas a lei mesma não depende." (DRETSKE, 1977, p. 255).

Desse modo, o necessitarismo se compromete com uma posição realista acerca dos universais. A exposição mais bem-acabada dessa teoria das leis encontra-se na obra de Armstrong (1983), What is a law of nature? Para o autor, tanto os universais de primeira-ordem quanto os de ordem superior (relações) devem obedecer ao princípio de instanciação: "Uma propriedade deve ser uma propriedade de um particular real; uma relação deve ser válida entre particulares reais.” (ARMSTRONG, 1983, p. 82). Dito de outro modo, Armstrong considera legítima apenas a postulação de universais instanciados. Nesse sentido, "ser um cavalo" é admitido como um universal real, ao passo que o mesmo não ocorre com o predicado "ser um unicórnio". ${ }^{1}$ De modo análogo, o princípio da instanciação é válido também para as leis, uma vez que, como vimos, estas são identificadas a universais de segunda-ordem. As leis possuem, portanto, a forma $N(F, G)$, na qual $F$ e $G$ são universais de primeira-ordem. Se a relação $N$ for válida, isto é, se $N$ descrever uma lei da natureza, a presença do universal $F$ implicará necessariamente a presença do universal $G$.

O necessitarista deve explicar, pois, de que forma uma relação pode ser instanciada em casos particulares. Segundo Armstrong (1983, p. 97), assim como o universal F é obtido pela abstração dos estados de coisas que instanciam tal universal, isto é, $\{F a$, $F b, \ldots, F n\}$, o universal de segunda-ordem $N(F, G)$ é instanciado nas sequências causais

1 Nem todos os defensores do necessitarismo defendem o princípio de instanciação. Tooley (1977) sustenta uma concepção platonista dos universais e das leis. Neste artigo, porém, irei me restringir à abordagem de Armstrong, uma vez que esta é tida como referencial na literatura sobre as leis. 
particulares $\{N(F a, G a), N(F b, G b), \ldots, N(F n, G n)\}$. Em outros termos, se for uma lei que “O cloreto de sódio é solúvel em água” (seja F “ser cloreto de sódio” e G “ser solúvel em água”), então a relação $N(F, G)$ será instanciada em cada sequência causal em que a adição de cloreto de sódio à água cause a dissolução do sal. Entretanto, Armstrong não afirma que possamos reduzir a lei geral aos casos particulares em que as sequências causais sejam observadas (admitir a redução implicaria regresso ao regularismo). Os casos particulares, portanto, exemplificam a lei, uma vez que "leis são universais, e portanto abstrações dos particulares que instanciam tais universais." (ARMSTRONG, 1983, p. 91). Logo, Armstrong afirma que a relação entre a lei e suas instâncias se dá de modo automático.

De acordo com o princípio de instanciação, um universal só existe se possui instâncias positivas. Logo, os universais são contingentes (cf. ARMSTRONG, 1983, p. 126). Isto é, em outros mundos possíveis, poderiam existir outros universais (distintos dos que existem no mundo atual). Essa conclusão decorre do fato de que os objetos que existem no mundo atual poderiam ser diferentes e, dessa maneira, instanciar outros universais. Diante disso, como o necessitarismo explica a necessidade envolvida nas leis da natureza? Dizer que $N(F, G)$ é uma relação de necessitação equivale a dizer que, no nosso mundo atual, a presença do universal $F$ implica necessariamente a presença do universal G. No entanto, num mundo possível distinto, é perfeitamente possível que $N(F, G)$ não expresse uma lei da natureza. Armstrong explica essa questão nos seguintes termos: “Se os universais $F$ e $G$ são relacionados de modo contingente, então eles podem, por definição, ser diferentemente relacionados em mundos possíveis diferentes." (ARMSTRONG, 1983, p. 80). Naturalmente, isso não equivale a dizer que instâncias do universal podem ser diferentes em nosso mundo, pois o autor considera que não faria sentido dizer que uma instância adquiriu (ou perdeu) um universal. Em última análise, Armstrong afirma que as leis da natureza apontam para uma necessidade existente em nosso mundo, todavia elas mesmas não são necessárias em todos os mundos possíveis.

A contingência das leis da natureza decorre do compromisso de Armstrong com a tese do monismo categórico (MC), isto é, a afirmação de que todas as propriedades são categóricas. Em outros termos, Armstrong admite que uma propriedade implica a atribuição de certos poderes (ou disposições) às entidades que as instanciam, todavia, a identidade da propriedade é independente da atribuição dessas disposições: 
“Propriedades são contidas em si mesmas, não apontando para além de si mesmas na direção de outros efeitos gerados a partir dessas propriedades.” (ARMSTRONG, 1997, p. 80). Em última análise, não há disposições no nível ontológico mais fundamental. Uma consequência dessa posição é o que se costuma denominar quidditismo, visto como problemático pelos defensores do disposicionalismo. A recusa da realidade independente das disposições, tese própria do MC, implica tomar a identidade das propriedades como primitiva, isto é, como um fato bruto sem relação de dependência com fatores modais. Esse primitivismo na definição da identidade das propriedades é denominada por Bird e outros disposicionalistas como quidditismo, segundo o qual “a identidade e unicidade das propriedades é um fato bruto, não fundado em diferenças qualitivas.” (BIRD, 2007, p. 3). Nesse sentido, o categorialista postula como fundamental somente a própria constituição interna das propriedades, denominada sua quidditas. A principal objeção ao quidditismo (e, de modo mais geral, ao MC) tem como ponto de partida a afirmação de que o discurso sobre modalidades é parte fundamental da ciência. Segundo Ellis, as ciências (especialmente a física e a química) fornecem evidências suficientes para crermos que as propriedades mais fundamentais da natureza são disposicionais (cf. ELLIS, 1999, p. 25-26). Assim, se aceitarmos o ponto de vista realista segundo o qual um dos objetivos da ciência é desvendar as propriedades fundamentais da natureza, então o disposicionalismo passa a ser a proposta metafísica em maior conformidade a essa tarefa. Tomando o caso da química como referência, Ellis argumenta que parte da tarefa científica de investigar os compostos moleculares ou iônicos - tais como a água $\left(\mathrm{H}_{2} \mathrm{O}\right)$ ou o cloreto de sódio ( $\left.\mathrm{NaCl}\right)$, respectivamente - consiste precisamente em determinar o comportamento de tais compostos em determinadas reações químicas. Em última análise, a identidade dos compostos é determinada pela sua estrutura, que determina o modo característico como tal composto participa de certas reações. Por exemplo, na eletrólise da água, sempre ocorre a liberação de hidrogênio e oxigênio na mesma proporção, a saber, dois átomos de hidrogênio para um de oxigênio. Na visão disposicionalista, essa proporção caracteriza uma disposição essencial da molécula de água. Portanto, o disposicionalista acusa o Monismo Categórico de não ser capaz de capturar essa ligação essencial entre a natureza de um objeto físico e as suas disposições internas, visto que o MC toma tal ligação como contingente. Com efeito, a tese do quidditismo implica que tudo 
o que pode ser dito sobre a natureza de uma propriedade é o fato dela ser idêntica a si mesma e distinta das outras, o que não corresponde aos objetivos da investigação científica, ao menos como a caracteriza o disposicionalista (cf. BIRD, 2007, p. 55).

Veremos, na seção seguinte, que a visão disposicionalista das leis considera a contingência das leis como um ponto fraco da concepção DTA. Tal contingência é derivada do compromisso dos defensores da DTA com o categorialismo. Em última análise, o essencialista acusa a metafísica de Armstrong de ser “fraca demais", de modo a não assegurar que as leis sejam necessárias em todos os mundos possíveis.

\section{LEIS FUNDADAS NAS ESSÊNCIAS: O ESSENCIALISMO DISPOSICIONAL}

Segundo o essencialista disposicional, a identidade de algumas propriedades é definida em termos das interações causais das quais o objeto que instancia tal propriedade pode participar. Assim, a verdade de enunciados como “o metal $x$ sofreu dilatação após ser aquecido" seria explicada pela existência de uma disposição essencial ao objeto em questão. Tal propriedade consiste na atribuição de um poder causal ao metal $x$, qual seja, a disposição de manifestar necessariamente determinado efeito (nesse caso, a dilatação) ao serem satisfeitas condições específicas (no exemplo, o aumento de temperatura).

Desse modo, os defensores do ED sustentam que as propriedades fundamentais da natureza (algumas, ao menos) são disposicionais. Além disso, afirmam que as ciências reforçam esse ponto de vista. Por essa razão, tal raciocínio é chamado o argumento da ciência em favor do ED, tal como explicita Ellis: “Todos as coisas mais fundamentais que conhecemos possuem poderes causais ou outras propriedades disposicionais, e, até onde sabemos, elas possuem apenas tais propriedades." (ELLIS, 2002, p. 74) Segundo Bird, embora o pensamento clássico privilegie a visão do espaço e do tempo como passivos (isto é, como pano de fundo para os acontecimentos físicos, sem qualquer princípio de atividade), a teoria da Relatividade Geral endossaria a alternativa de que espaço, tempo e demais propriedades possam ser caracterizados em termos de suas propriedades dinâmicas, identificadas com as disposições para afetar o comportamento de objetos que ocupem determinado ponto ou estado.

Enquanto Armstrong considera que as disposições dos objetos sobrevêm das suas propriedades categóricas e das leis da natureza, os defensores do ED invertem essa 
relação: para eles, as leis da natureza são sobrevenientes das essências disposicionais dos objetos. Suponhamos que o enunciado P (e.g. “Todos os metais dilatam quando aquecidos”) descreva uma lei da natureza ou seja consequência de um conjunto de leis da natureza. Seja $x$ uma amostra de cobre submetida a aquecimento. Logo, segundo o categorialismo, a expectativa de que $x$ sofra dilatação é explicada por dois fatores: (i) pelas propriedades categóricas de $x$, e (ii) pelo fato de P descrever uma lei da natureza, seja ela compreendida como uma regularidade (Lewis) ou uma relação entre universais (Armstrong). Em outras palavras, a disposição não é essencial ao metal em questão, mas sobrevém da base categórica. Esse modo de sobreveniência implica afirmar que a disposição do metal $x$ para sofrer dilatação depende das leis da natureza e do modo como elas se aplicam às circunstâncias em questão (cf. ELLIS, 2002, p. 3). Se as leis da natureza fossem diferentes (em outro mundo possível, por exemplo), as disposições do objeto $x$ também o seriam. Os poderes causais de um objeto, portanto, sobrevêm das leis da natureza. Em outros termos, num mundo possível em que (i) metais existam e (ii) o enunciado P não descreva uma lei da natureza, é possível que os metais não sofram dilatação quando aquecidos. Logo, afirmar que a concepção DTA concebe as propriedades disposicionais como redutíveis às categóricas significa conceder que, em mundos possíveis diferentes, o mesmo objeto possa existir com propriedades disposicionais diferentes.

De acordo com o ED, tal conclusão é inaceitável. Segundo essa abordagem, se o enunciado P descreve uma lei da natureza, então P é metafisicamente necessário. Logo, se é uma lei da natureza que a água dissolve o sal, então a água dissolve o sal em todos os mundos possíveis. Não é possível sustentar simultaneamente o disposicionalismo sobre propriedades e a visão contingente das leis da natureza. Dito de outro modo, a existência de “moléculas de água” seria impossível num mundo no qual a água não dissolva o sal, uma vez que se os poderes causais de um objeto são diferentes, as leis também o serão. Se, num mundo possível, um objeto não possuir o poder causal de dissolver o sal (alternativamente, se a lei segundo a qual a água dissolve o sal for falsa), tal objeto não pode ser identificado à “água” (cf. CHAKRAVARTTY, 2003, p. 403). Para o disposicionalismo, um mundo em que a água não dissolva o sal é, em última análise, um mundo impossível. Em mundos genuinamente possíveis, ou a água existe (sendo capaz de dissolver o sal) ou não existe. 
Com efeito, a concepção disposicionalista das leis choca-se com a ideia, partilhada por muitos filósofos, de que as leis da natureza poderiam ser diferentes. É necessário, portanto, retomar a distinção entre leis científicas e leis da natureza. O primeiro conceito refere-se aos enunciados que atestam regularidades e que dependem da investigação científica. Naturalmente, leis científicas são falseáveis, passíveis de revisão. Quando o essencialista atribui caráter metafisicamente necessário às leis, refere-se às leis da natureza, isto é, aos truthmakers das leis científicas. Se as leis científicas forem verdadeiras, o que as torna verdadeira são leis da natureza, e estas são provenientes das essências, logo metafisicamente necessárias. Não há contradição em admitir, por um lado, que as ciências (e as leis científicas) são falíveis e, por outro, que as leis da natureza são metafisicamente necessárias.

Segundo Ellis, a origem do estranhamento acerca dessa tese reside numa interpretação dos argumentos de Hume sobre a relação de causalidade. Analisando os raciocínios sobre questões de fato, o autor das Investigações argumenta em favor do hábito como fundamento de nossas inferências sobre causa e efeito. Enquanto as relações de ideias são regidas pelo princípio de não-contradição, questões de fato demandam recurso à observação a fim de serem verificadas. Desse modo, generalizações empíricas como “Todo F é G” - mais precisamente, $Đ x(F x Đ G x)$ - sempre admitiriam a possibilidade (lógica) de que haja um particular a tal que Fa e $\mathrm{Ga}$. Logo, a generalização em questão não poderia ser considerada metafisicamente necessária (aliás, a própria ideia de necessidade metafísica é inaceitável nessa perspectiva), visto que Hume e seus seguidores consideram não haver um princípio lógico para afastar a possibilidade real de que a generalização seja falseada, neste ou em outros mundos possíveis. Tal argumento figura na base da teoria regularista das leis da natureza. Portanto, se o ED busca sustentar a necessidade metafísica das leis, é preciso explicar o fato de que, se a proposição “Todo $F$ é G” expressa uma lei, então é impossível que haja um particular a tal que $F a$ e $\sim G a$.

A estratégia de Ellis para lidar com essa questão é analisar o conceito de possibilidade metafísica/real. De acordo com o ponto de vista essencialista, o fato de sermos capazes de imaginar determinados estados de coisas não é suficiente para considerá-los realmente possíveis. Assim, o autor afirma que os argumentos de Hume se fundamentam na possibilidade epistêmica (isto é, a possibilidade de algo ser imaginado e conhecido por todos). No entanto, considerações meramente epistêmicas não têm implicações 
sobre a possibilidade real (aquilo que pode, efetivamente, ser o caso), de modo que as conclusões humeanas tomam equivocadamente as duas categorias de possibilidade como idênticas. Do ponto de vista do ED, se a capacidade de sofrer dilatação quando aquecido for uma disposição essencial aos metais, então mesmo que seja possível imaginar um mundo possível no qual metais não sofram dilatação térmica, tal imaginação não denota uma possibilidade efetiva do ponto de vista metafísico. Em última análise, o disposicionalismo implica uma análise mais restritiva da ideia de possibilidade metafísica. Uma vez que a identidade dos objetos depende de suas disposições intrínsecas, os estados de coisas admitidos como possíveis serão restritos àqueles que correspondem às naturezas essenciais dos objetos. Logo, a imaginação não é parâmetro adequado para determinar o que é genuinamente possível. Ellis expressa essa conclusão nos seguintes termos:

Se a identidade de um objeto depende daquilo de ele é feito, ou do modo como ele se constitui, então sua identidade deve depender, em última análise, dos poderes causais, das capacidades e das propensões dos seus constituintes. Isto é, o objeto não seria o que ele é caso seus constituintes não tivessem tais poderes causais. Portanto, as possibilidades de comportamento de tal objeto devem ser restritas pela sua natureza, e não determinadas pelos poderes de nossa imaginação. (ELLIS, 2002, p. 112-113)

Uma vez que as leis da natureza sobrevêm das naturezas essenciais dos objetos, e estas incluem suas disposições, então a necessidade envolvida nas leis é a chamada necessidade de re, isto é, leis são necessárias em virtude da natureza dos objetos, e não em virtude do que é dito sobre os objetos (necessidade de dicto). A análise das disposições fornece, portanto, as bases para uma fundamentação metafísica da noção de lei da natureza.

\section{CONSIDERAÇÕES FINAIS}

Neste artigo, procurei mostrar as diferenças e aproximações entre necessitarismo categorialista e essencialismo disposicional, no que tange ao Realismo Nomológico. Tanto a DTA quanto o ED concordam na afirmação de que as leis não são baseadas nas uniformidades, mas em algo além delas. Dito de outro modo, ambas as versões de RN fornecem razões para acreditarmos que leis científicas, se verdadeiras, são tornadas verdadeiras pelas leis da natureza, no sentido de que, caso as generalizações obtidas pelas 
ciências forem verdadeiras, as duas concepções apontam os truthmakers de tais leis. No entanto, as explicações fornecidas pela visão DTA e pelo ED ao comportamento regular dos objetos operam em direções opostas: para o ED, a direção da explicação é “de baixo para cima” (bottom-up), isto é, dos objetos - com suas essências disposicionais - para as leis (sobrevenientes das essências); na concepção DTA, a explicação parte dos universais de segunda-ordem - $N(F, G)$ - para os universais de primeira-ordem, instanciados pelos objetos; a direção, pois, é “de cima para baixo” (top-down).

Na perspectiva necessitarista, as leis são como que "impostas" por um universal de ordem superior aos objetos da natureza. Tal característica da visão DTA das leis faz com que não haja fundamento metafísico suficiente para estabelecer as leis como necessárias em todos os mundos possíveis. Por essa razão, considero mais vantajosa a fundamentação realista das leis oferecida pelo essencialismo, uma vez que as leis não precisam ser impostas de fora aos objetos, mas fluem de sua própria natureza essencial.

\section{REFERÊNCIAS}

ARMSTRONG, D. M. A world of states of affairs. Cambridge: Cambridge U. Press, 1997. What is a law of nature? Cambridge: Cambridge U. Press, 1983.

BIRD, A. Nature's metaphysics: laws and properties. Oxford: Clarendon Press, 2007.

CHAKRAVARTTY, A. “The Dispositional Essentialist View of Properties and Laws”. International Journal of Philosophical Studies. v. 11, n. 4, 2003, p. 393-413.

DRETSKE, F. I. “Laws of nature”. In: Philosophy of Science, vol. 44, n. 2, 1977, p. 248-268.

ELLIS, B. “Causal powers and laws of nature”. In: SANKEY, H. (Org.) Causation and laws of nature. Dordrecht: Kluwer Academic Publishers, 1999, p. 19-34. (Australasian Studies in History and Philosophy of Science, 14).

. The philosophy of nature: a guide to new essentialism. Chesham: Acumen, 2002. 
GHINS, M. Uma introdução à metafísica da natureza: representação, realismo e leis científicas. Trad. Eduardo S. O. Barra e Ronei C. Mocellin. Curitiba: Editora UFPR, 2013.

HUME, D. Investigações sobre o entendimento humano e sobre os princípios da moral. Trad. José Oscar de Almeida Marques. São Paulo: UNESP, 2004 [1748].

LEWIS, D. Philosophical papers II. Oxford: Oxford University Press, 1986.

TOOLEY, M. “The nature of laws”. In: Canadian Journal of Philosophy, vol. 7, n. 4, 1977, p. 667-698. 